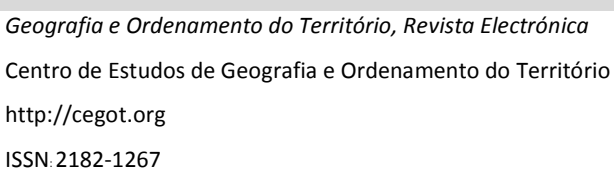

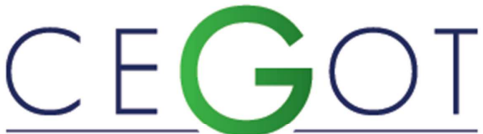

Centro de Estudos de Geografia e Ordenamento do Território
VALENÇA, MÁRCIO

Departamento de Políticas Públicas da Universidade Federal do Rio Grande do Norte Campus Universitário Lagoa Nova, CEP 59078-970 / Natal/RN - Brasil

marciovalenca10@gmail.com

\title{
Da dialética socioespacial à justiça espacial. Apontamentos sobre a trajetória acadêmica de Edward W. Soja
}

From the socio-territorial dialectic to spatial justice. Notes on the academic career of Edward W. Soja

Referência: Valença, Márcio (2015). Da dialética socioespacial à justiça espacial. Apontamentos sobre a trajetória acadêmica de Edward W. Soja. Revista de Geografia e Ordenamento do Território (GOT), n.o 8 (dezembro). Centro de Estudos de Geografia e Ordenamento do Território, p. 5-10. dx.doi.org/10.17127/got/2015.8.001

Mais comumente conhecido por Ed, Soja se tornou um nome celebrado na geografia (em particular urbana) e nas ciências sociais, com o livro Geografias Pós-modernas, publicado em 1989. O livro é tido como emblemático do movimento conhecido como "virada espacial" nas ciências sociais. A sua base epistemológica se distancia da economia política modernista com foco único na história e de subordinação do espaço ao tempo, para propor uma "dialética socioespacial", contribuindo, com sua geografia marxista, para a consolidação de uma teoria social crítica. Assim é possível vislumbrar um materialismo histórico-geográfico como também uma geografia histórica do capitalismo. A proposta do autor foi igualmente chamada de materialismo geográfico pós-moderno, humanístico crítico. O próprio Soja se refere de várias outras maneiras ao movimento que ajudou a criar: pós-modernismo crítico, geografias alternativas, geografia humana crítica, multifacetada e inclusiva etc., indicando 
haver uma certa abertura de interpretação dos muitos conceitos elaborados ou do que chama "imaginações geográficas".

Desde o lançamento, o livro atraiu muita atenção e crítica. Soja (2006) meio que ironiza ao tentar explicar que suas ideias receberam muitas críticas dos colegas da mesma geração (professores já estabelecidos) enquanto os mais jovens adotaram essas ideias amplamente e expandiram suas imaginações geográficas em várias direções. Diz não saber ao certo da influência que teve, mas comenta sobre o que se sucedeu na geografia, na década seguinte ao lançamento do livro: "Nunca antes a imaginação geográfica foi tão disseminada e influente como é hoje e, talvez, como nunca antes, a disciplina de geografia foi tão diversa e criativamente aberta a uma multiplicidade de perspectivas alternativas" (p.820). O livro - um grande sucesso editorial e um dos mais importantes da sua geração - teve, por certo, influência nos destinos da geografia nos anos seguintes à sua publicação.

O livro é o ajuntamento de vários ensaios - todos revisados e ampliados - que o autor já havia publicado durante a década de 1980 . Soja percorre longo e seguro caminho para estabelecer a sua proposta epistemológica, encontrando os embriões de sua análise, no final da década de 1960. Infelizmente, lamenta-se, logo nas primeiras páginas do livro: "...a virada espacial estranhamente permaneceu muda pela reafirmação não problematizada da primazia da história sobre a geografia, que se referia tanto ao marxismo ocidental, quanto às ciências sociais liberais" (p.13). Esta situação só iria mudar, segundo explica, uma década depois.

Soja então resgata autores cujas análises eram centradas no espaço para localizar as origens de suas "geografias pós-modernas". O filósofo Henri Lefebvre - a sua principal referência -, o crítico de arte John Berger, o crítico literário Fredric Jameson, o sociólogo Anthony Giddens e o filósofo Marshall Berman estão entre alguns dos autores de sua referência. Discute, igualmente, textos, aulas e entrevistas de Michel Foucault. O filósofo e teórico social francês dedicou muito do seu tempo a estudar a relação entre espaço e poder, avançando numa visão pós-marxista. Para ele, espaço não é único; há vários espaços, todos heterogêneos, não exclusivos, não superpostos, embora possam ser justapostos. Espaço é, assim, um conceito relacional. Por exemplo, o espaço da "heterotopia", ou seja, espaço singular onde se desenvolvem sistemas muitas vezes antagônicos ao do establishment, é um "outro", não 
necessariamente o oposto deste último. Em suma, Foucault é patente em considerar uma potente interseção de tempo e espaço no exercício do poder. Essas ideias, em muito subversivas, são marcantes para a obra de Soja, em particular, em como o termo "pósmodernidade" é compreendido. Assim, como Foucault, Soja discorda de que o espaço seja morto, imóvel e não dialético - como muitos o consideravam -, enquanto o tempo é fecundo, vivo e dialético. Para Foucault e Soja, ambas as dimensões são partes indissociáveis da vida social.

Acompanha a modernidade uma metanarrativa do tempo. O tempo aqui é linear, em sucessão. O tempo é o fazer histórico; o espaço é secundário - uma localização onde o tempo se realiza. A partir do final dos anos 1960, o balanço entre tempo e espaço se desfaz, inaugurando novas configurações socioespaciais. Isto se evidencia no que Soja chama de "geografias pós-modernas". Estas são as várias manifestações de um novo mundo, de maior complexidade, em formação. A ideia de pós-modernidade é crítica para a compreensão desta nova configuração. $\mathrm{O}$ autor apresenta várias definições do termo, mas o que interessa é que este designa um mundo de múltiplas determinações, de natureza caótica, desordenada e aleatória. Tal caleidoscópio não pode mais ter uma representação única: é multitextual. As teorias que tentam explicar este conjunto de representações ou mesmo uma de suas partes não são mais permanentes, mas transientes. Ou seja, devem mudar com a velocidade de sua transformação. Há aqui, segundo alguns comentadores da obra de Soja, uma contradição, já que o marxismo, como uma metateoria, que é concernente à obra de Soja, não consegue mais dar conta do mundo contemporâneo.

Na pós-modernidade, o espaço é uma colagem, um contexto, favorecendo os localismos. É por aí que é possível ver como a reestruturação produtiva do capitalismo flexível determinou novas (re)configurações regionais e urbanas. A espacialidade do desenvolvimento capitalista muda e se fixa (mesmo que provisoriamente) em diferentes direções e escalas. São as tais "geografias pós-modernas". A capacidade de movimento do capital é, assim, determinante do aprofundamento das desigualdades; o trabalho não se adapta da mesma forma. O capital transforma os lugares, sítios de resistência, em espaço abstrato. Para concretizar esta narrativa, Soja discute Los Angeles, cidade que entende ser exemplo extremo de cidade polinucleada e amorfa; cidade de contrastes onde coexistem os 
super lucros corporativos e a desigualdade social, os super ricos, ligados a indústrias de alta tecnologia e setores financeiros, e os trabalhadores imigrantes de muitas partes do globo, em particular mulheres, com baixos salários, empregados nas indústrias de baixa tecnologia e serviços inferiores. Diante de tantas novas e velhas configurações, Los Angeles é, como define o autor, como no Aleph de Borges: todos os espaços no mesmo ponto.

O livro de Soja não aparece sozinho. A ideia de assegurar o lugar próprio da geografia na teoria social crítica não foi um movimento solitário do autor. Antes dele, David Harvey, da aclamada Johns Hopkins University, outro nome de peso da Geografia e da mesma geração, já havia dado passos importantes nesta direção, mas a contribuição de Soja e a militância na geografia (desde uma instituição internacional de peso, a University of California, Los Angeles, UCLA) -, por certo, adicionaram novos temperos ao movimento. Eu arriscaria dizer que o sucesso do livro de Soja se beneficiou do lançamento de A condição pós-moderna, de Harvey, no mesmo ano. Ambos os livros e autores ganharam a cena na discussão sobre a virada espacial no contexto da pós-modernidade, mantendo-se fiéis à ortodoxia da Geografia crítica marxista - Harvey mais, Soja menos. Outro lançamento importante, no mesmo ano de 1989, e que compõe com os dois livros já mencionados, foi a obra The informational city, de outro expoente das ciências sociais, muito caro à Geografia, o sociólogo Manuel Castells (University of California, Berkeley).

Isso nem sempre é reconhecido, ou é um ponto em disputa, mas o sucesso da virada espacial, do materialismo histórico-geográfico, da dialética socioespacial, ou como queiram chamar, seguiu os rumos do capitalismo contemporâneo, com os diversos experimentos que foram postos em prática em seguida ou em meio à crise do fordismo, a partir do final da década de 1960. A maior abertura para fora das economias fordistas do pós-guerra, permitida por revolucionária inovação nos setores de transportes e comunicações, levou ao que é hoje genericamente chamado de globalização. Muitos desses experimentos, tendo por base novas tecnologias e formas de organização do trabalho, só se consolidaram e puderam ser vistos, reconhecidos e analisados, anos mais tarde. As obras (livros, artigos etc.) que se dedicaram a explicar as saídas da crise do fordismo não tinham mais como ignorar a nova geografia do desenvolvimento regional e urbano. 
Embora já fosse um acadêmico conhecido no campo da geografia do desenvolvimento, principalmente pelos trabalhos sobre a modernização e economia política do Kenya, que havia realizado em finais da década de 1960 e 1970, foi com o livro Postmodern geographies que Soja ganhou amplo reconhecimento internacional. Com os livros seguintes, em particular Thirdspace (de 1996) e Postmetropolis (de 2000), Soja completou uma trilogia. Estes últimos são incursões mais detalhadas sobre aspectos do primeiro livro aqui já comentado e que não foram tratados, ou que foram revisados ou aprofundados, em particular no que diz respeito ao pensamento espacial de Lefebvre e à discussão de Los Angeles como paradigma da cidade pós-moderna. A ideia de pós-metrópole, por exemplo, já havia aparecido em Postmodern geographies, na análise da polinucleada Los Angeles. Em Seeking spatial justice, livro publicado em 2010, Soja não abandona seu projeto de trazer a geografia para o centro da análise e avança na discussão das consequências de movimentos sociais urbanos no setor dos transportes públicos em luta pelo direito à cidade em Los Angeles. Retoma assim o tema de Lefebvre sobre o poder inerente ao comando do espaço.

Muitas ideias contidas na breve discussão acima, que é apenas um esboço genérico e sem aprofundamento da principal obra de Ed Soja, podem parecer óbvias para o leitor da geografia hoje. Ao longo dos anos, elas têm sido disseminadas e dispersas nas dissertações, teses, livros e artigos da disciplina e ciências sociais em geral, mas por certo foram novidades quando formuladas. Ed Soja não ganhou a fama que tem a toa. E não foi por acaso que foi convidado, em 2010, para fazer parte da Comissão Permanente de Aconselhamento do Centro de Estudos sobre Geografia e Ordenamento Territorial (CEGOT). No ano seguinte, Soja esteve em Coimbra para participar do primeiro seminário de avaliação, contribuindo para a consolidação do Centro, ao final de seu primeiro triênio de existência. Este texto é um justo reconhecimento e agradecimento por sua atuação como conselheiro do CEGOT.

Os últimos anos viram a despedida de grandes geógrafos, referências críticas de nossa geração: Milton Santos, Maurício de Almeida Abreu, Peter Ambrose, Neil Smith, Peter Hall, António Gama Mendes e, agora, Ed Soja. Todos partiram cedo, prematuramente, quando se mantinham ainda bastante produtivos, dedicando-se à academia com produção intelectual de referência, qualificada e marcante. Partiram no momento mais maduro e brilhante de 
suas vidas intelectuais. Deixam, no entanto, um legado intelectual que permanecerá por muito tempo, já que constitui parte importante da formação de várias gerações de profissionais e acadêmicos, inclusive os ainda bem jovens. Esses grandes geógrafos são referências obrigatórias para a nossa e para as gerações futuras.

\section{Referências}

SOJA, Edward W. Postmodern geographies: the reassertion of space in critical social theory. New York: Verso, 1989. (Publicado também em português pela Editora ZAHAR, Rio de Janeiro, em 1993.)

SOJA, Edward W. Thirdspace - Journeys to Los Angeles and other real-and-imagined places. Oxford: Blackwell, 1996.

SOJA, Edward W. Postmetropolis - Critical studies of cities and regions. Oxford: Blackwell, 2000.

SOJA, Edward W. Classics in Human Geography revisited. (Soja, E.W. 1989: Postmodern geographies: the reassertion of space in critical social theory. London: Verso). Progress in Human Geography, v.30, n.6, 812-820, 2006.

SOJA, Edward W. Seeking spatial justice. Minneapolis: University of Minnessota Press, 2010. 